\title{
Research on the Innovation and Development of Visual Communication Design in the New Media Era
}

\author{
Ziyan Zhang ${ }^{1}$ Wenbo $\mathrm{Hu}^{2}$ Zhe Yang* \\ ${ }^{1}$ School of Creative Design, Hainan Tropical Ocean University, Sanya, China. \\ 2School of International Cooperation, Hainan Tropical Ocean University, Sanya, China. \\ Corresponding author E-Mail; zyang20202020@163.com
}

\begin{abstract}
With the continuous development of modern society and the emergence of various new technologies, people have gradually entered the new media era. In the era of new media, visual communication design has countless innovative ideas, but it also faces the test given by the development of the times. Visual communication design and the development of the new media era are closely linked. Therefore, this article will mainly discuss the innovation and development of visual communication design in the context of new media development, hoping to effectively promote the development of modern visual communication design.
\end{abstract}

Keywords: new media, visual communication, innovation

\section{INTRODUCTION}

The purpose of visual communication design is to ensure the effective transmission of information through aesthetics. With the transformation of information dissemination methods to the Internet age, new media platforms have provided new communication space for visual communication design. New methods and scope of visual communication have been extended to almost all media fields, and the design language has been redefined and analysis. In the new media environment, the sensory experience of the entire society has undergone tremendous changes, and the development of media technology has also had a great impact on the design methods and design concepts of traditional visual communication design [1].

\section{OVERVIEW OF VISUAL COMMUNICATION DESIGN IN THE NEW MEDIA ERA}

\subsection{Definition of visual communication design}

Visual communication design was born in the visual design conference held in Japan in 1960. Scholars who participated in the conference realized that in the continuous development of image media, visual and Image has begun to exist as an independent way of expression, so a more comprehensive design has begun to emerge, that is, "visual communication design". In visual communication design, not only graphic design, but also graphic design is included. Some other media such as internet, movies and TV. At present, the process of modernization is accelerating, and visual communication design is constantly enriched with the development of technology. It not only satisfies the essence of art design in modern society, but also begins to develop slowly in more directions[2].

\subsection{The main features of the new media era}

New media has effectively exerted its advantages in information technology and can fully meet the diverse needs of users. In the new media era, the number of new media users is also increasing, according to the 2019 survey data of iResearch. It shows that the number of new media users in China is on the rise. A huge user group participates in information dissemination, and the interaction between the media and the audience continues to increase, which also promotes the continuous development of visual communication design and fully satisfies the audience's aesthetics.

Of course, there is another notable feature in the context of new media, that is, people need to receive massive amounts of information every day, and only highquality and innovative Information can be accepted by users. Therefore, in the context of new media, visual creative design needs to continue to innovate and develop, establish new aesthetic methods, and meet the aesthetic needs of the audience, so as to highlight the era 
characteristics of visual communication design in the context of new media.

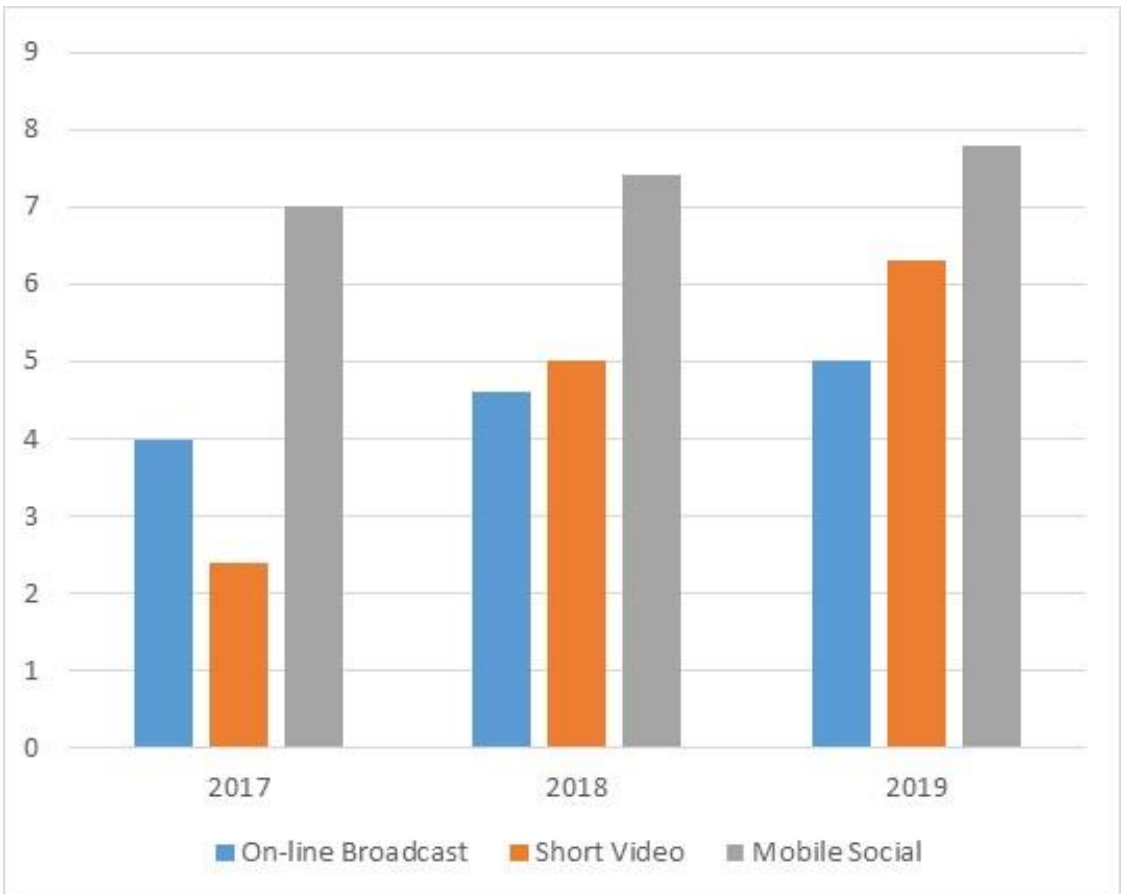

Figure 1 The scale of users in different fields of China's new media from 2017 to 2019 (unit: 100 million)

\section{THE IMPACT OF THE NEW MEDIA ERA ON VISUAL COMMUNICATION DESIGN}

\subsection{The design form is transformed from two- dimensional to three-dimensional}

In the visual communication design of traditional media, because relevant news information is mainly transmitted through newspapers and television, users can only interpret from a single dimension information, which makes media dissemination dominated by planes. In the era of new media, visual communication design is no longer limited to a single two-dimensional design. Designers can design a variety of visual communication schemes according to user needs, such as rational use of holographic technology, which is allowing users to achieve a three-dimensional reading experience, to participate in it actively, and then effective enhance the user's emotional experience and sense of participation[3].

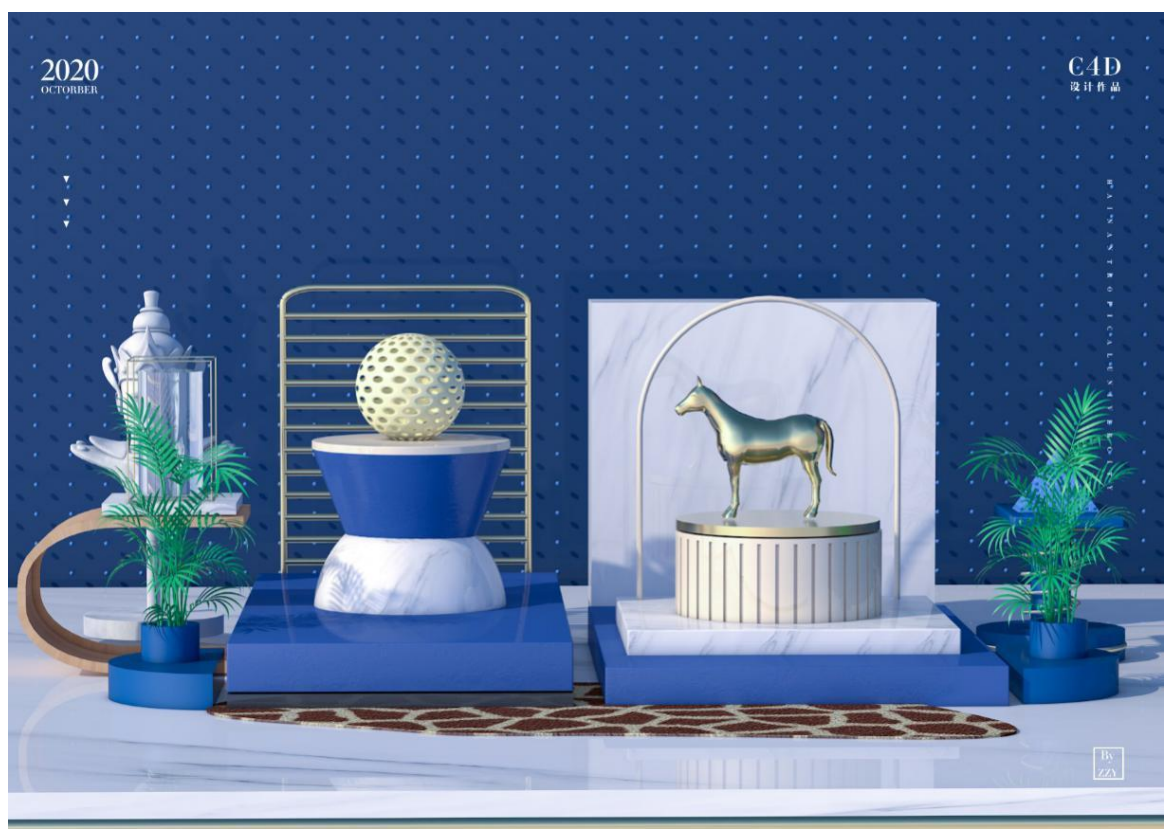

Figure 2 Three-dimensional Poster Design 


\subsection{Human-computer interaction, bringing fun to the audience}

In the past, when new media did not appear, users mainly used traditional paper media in the process of receiving information, but in modern society, a variety of media have emerged in the new media era, the application of new technology makes information dissemination interactive. According to the statistics shown in Figure3, when the public in China receives information, they generally use various social media and mobile phone clients. With the help of mobile phones and the Internet, users can actively participate in news information, realize information exchange. It also helps users solve the newsstyle reading experience more comprehensively, and realize the purpose of visual communication design.

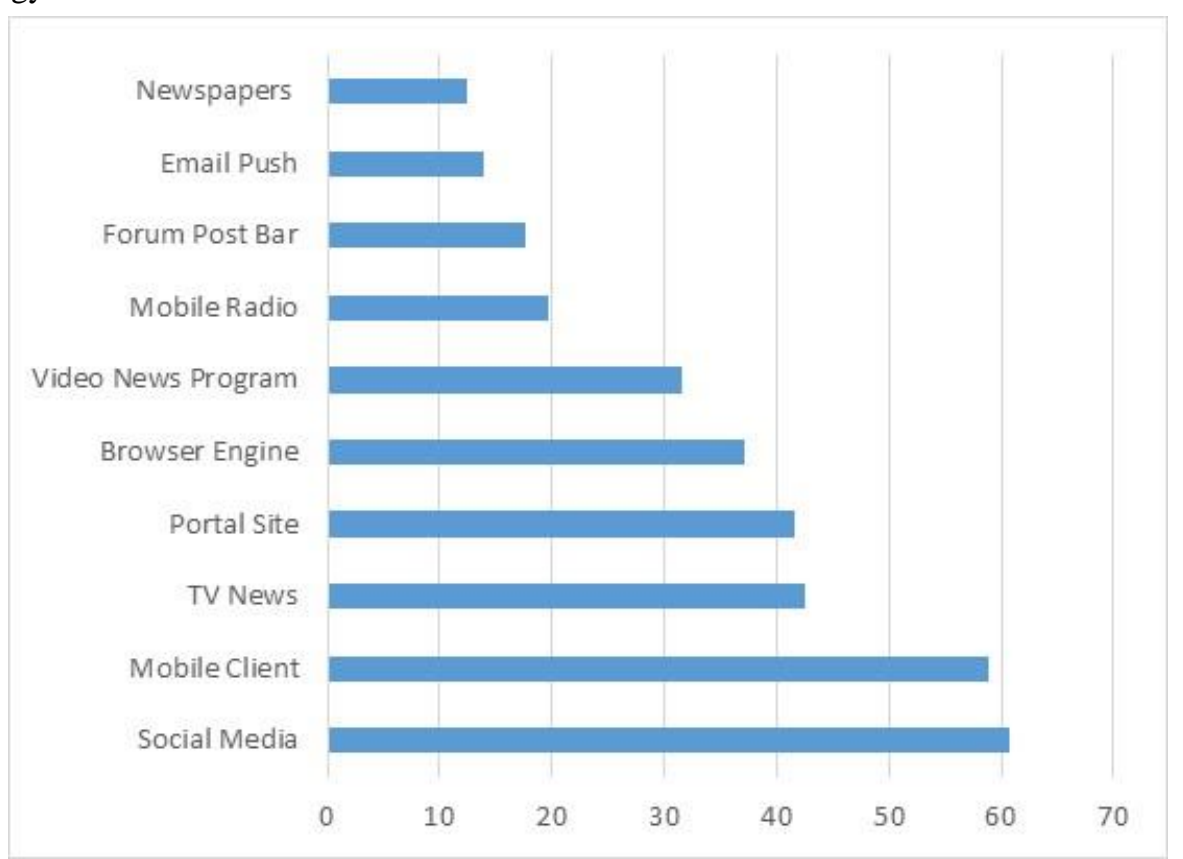

Figure 3 Channels for Chinese new media users to obtain information (sample size: 1727)

Data source: iResearch survey statistics.

\section{THE DEVELOPMENT TREND OF VISUAL COMMUNICATION DESIGN IN THE NEW MEDIA} ERA

In the new media era, with the help of information technology, visual communication design has achieved a leap development, both the design form and the communication method have been innovated, which has promoted the development of social civilization. In the future, society will continue to develop, and new media will continue to advance. In the era of new media, visual communication design will also achieve greater development [4]. The main development trends are shown in Table 1.

Table 1 The development trend of visual communication design in the new media era.

\begin{tabular}{ll}
\hline \multicolumn{1}{c}{ Development Trend } & \multicolumn{1}{c}{ Results } \\
\hline \multirow{2}{*}{$\begin{array}{l}\text { 1. According to the diverse needs of users, different design } \\
\text { elements are used flexibly to achieve the best visual } \\
\text { of design }\end{array}$} & $\begin{array}{l}\text { communication design effect. } \\
\text { 2. Continuously absorb new design concepts and implementation } \\
\text { methods, broaden design ideas, and achieve innovative designs. } \\
\text { 3. Map segmentation of user groups, carry out the visual } \\
\text { communication design work accurately, and ensure that the visual } \\
\text { communication design is creative, artistic and individual. }\end{array}$
\end{tabular}




\begin{tabular}{ll}
\hline 1.The content of information dissemination has gradually changed \\
from static to dynamic. \\
2. Reasonable use of modern design technology and systems to \\
formulate a reasonable visual communication design plan to \\
strengthen the interaction between users and the main body of \\
communication; \\
3. Set a personalized visual communication interface, highlight the \\
effective combination of users and media, and construct a new \\
version of national communication. The media field, realize the leap \\
of media communication.
\end{tabular}

\begin{tabular}{ll}
\hline Virtual design & 1.Cross-integration of multi-domain information to create an \\
immersive virtual reading experience for users and deepen user \\
information acquisition experience. \\
2.Digital information technology and virtual technology integration, \\
users can read in multiple dimensions and read information from \\
multiple perspectives. \\
3. The virtual scene makes information presentation visible and \\
concrete, and users can understand information in the virtualized \\
space.
\end{tabular}

\section{CONCLUSION}

With the continuous development of modern new media technology, it has promoted the renewal of visual communication design. The expression forms, design concepts, and communication methods of visual communication design have fully met the actual needs of the audience. In the modern multimedia era, if visual communication design wants to achieve greater development, it must promote its development in the direction of diversification, integration, virtualization, dynamics and interactivity, and strive to create an immersive reading experience for customers and enhance users [5]. In this way, it can effectively realize the further development of modern visual communication design.

\section{REFERENCES}

[1] Wang Junjie. (2011). Visual Communication Design under the Impact of New Media Art Design, Art and Design: Theory, 69-71.

[2] Jiang Jie. (2014). On the Influence of New Media on Visual Communication Design [J]. Popular Literature and Art, 131-132.

[3] Huang Ying Wang. (2017). Research on the Development Trend of Visual Communication
Design in the New Media Era[J]. Popular Literature and Art, 50.

[4] Ren Yufeng. (2018). On the development of new media visual communication design and the development of visual communication design, literary life: Wenhai Yiyuan, 143-144.

[5] Zhao, Y., \& Yang, X. G. (2014). Research on digital media technology in the folk-art design. Advanced Materials Research, 926-930. 